\title{
Knowledge Management Application and Its Effect on Internal Processes Effectiveness
}

\author{
Mohammad Theeb Mubaideen \\ Correspondence: Mohammad Theeb Mubaideen, Assistant Professor, Department of Economics and \\ Administrative Sciences, Al-Zaytoonah University of Jordan, P. O Box: 130, Amman 11733, Jordan. Tel: \\ 962-77-767-7341.E-mail: mmubaideen58@yahoo.com
}

Received: August 7, 2012

doi:10.5539/ibr.v5n12p153

\author{
Accepted: October 3, 2012 \\ Online Published: November 14, 2012 \\ URL: http://dx.doi.org/10.5539/ibr.v5n12p153
}

\begin{abstract}
This study is aimed at investigating the application of knowledge management at the Arab Banking Corporation (ABC/Jordan), and its impact on the effectiveness of internal processes at the bank. The study sample consists of (450) employees working at the Arab Banking Corporation (ABC/Jordan). A special questionnaire was developed to collect the needed data from the study sample. The study revealed that the existence of knowledge management, and its effectiveness on internal processes, was significant. The results of the study also showed that there was an impact of statistical significance of (knowledge identification \& knowledge application) on the effectiveness of internal processes at the bank. On the other hand, there was no impact of statistical significance of (knowledge generation \& distribution of knowledge) on the effectiveness of internal processes at the bank.
\end{abstract}

Keywords: knowledge management, effectiveness of internal processes

\section{Introduction}

Knowledge is the essential foundation for building a competitive advantage in this era, where the winds of change are leading to rapid developments in all fields. Any organization needs knowledge to make decisions and solve problems. Perhaps the most distinguishing feature of this era is the vast amount of information and the ability to access this information easily and at low cost. However, merely getting the correct information is no longer enough to achieve a competitive advantage. Such an edge requires knowledge of how to make use of this information and put it in the appropriate framework. Only then would an organization achieve a competitive advantage (Khalili, 2006).

Information and knowledge are considered a resource investment and a source of national income. This is because they employ the full potential of information technology and modern communication, which have become one of the fastest growing sectors. The progress of countries can be measured by the extent of their progress in the areas of information and communication. Such progress affects economic and social development through the fundamental changes caused by $\mathrm{R} \& \mathrm{D}$, which is directly linked to the volume of available knowledge and information in science and technology. Information, in its various types and sizes, is considered the backbone of the decision-making process that is necessary to achieve economic progress and social well-being (Al-Amoush, 2009).

In order to be able to face arising challenges and unknown variables there has to be new measures for a business, which are put in place to face such challenges. Knowledge management and its applications are considered to be the greatest challenge of the 21 st century, where businesses and corporations seek to identify valuable information, analyse it, and use in its operations (Al-Faris, 2010).

The concept of knowledge application soon became a practical domain, more accustomed to dealing with fluid variables. This concept became even more important after the realization that having a competitive edge and sustaining it is based on the existence of new ideas in the first place, which is a function of the information database and the investment placed for its creation. This encourages continual innovation, both in the product itself and the after service. However, this knowledge on its own is not of value unless it is activated and tapped into by management through executive orders that turn it into a tool against the competition (Muhammad, 2010).

The effectiveness of internal processes has a great role in accomplishing the growth and success of a company, achieving high targets, and attracting new clients with increased loyalty. This is done by having a greater understanding of its internal processes (innovation, operation, social), within the framework of quality, price, and employee participation in providing solutions for the company's problems. The effectiveness of internal processes 
is defined as; "A collection of vital activities concerned with the creative, operational, and social aspects of the organization, which in turn reflects its potential for excellence and achieving its goals with regards to its customers and stakeholders" (Al-Kasasbeh, 2011).

Many studies confirm that adopting knowledge management in organizations achieves a number of benefits including; increased productivity, enhanced decision making, increased efficiency and performance, encourages innovation, increases competitiveness, and a greater overall resiliency in adapting to surrounding variables (Abu Khdeir, 2009).

The Arab Banking Corporation (ABC/Jordan) is considered one of the leading banks in Jordan. It is a Jordanian public shareholding company, and a member of the Arab Banking Corporation, one of the largest Arab Banks. The Arab Banking Corporation has subsidiaries, branches, and representative offices scattered all over the world, with about (25) branches in Jordan. Given the sensitivity of the banking sector operations, it is crucial that internal processes be as effective as possible. This requires looking into all the factors affecting the variables of knowledge management, which is certainly worthy of further investigation and study, particularly so in today's digital age.

Here we can say that the purpose of this study is investigating the application of knowledge management at the Arab Banking Corporation (ABC/Jordan), and its effect on internal processes at the bank.

\section{Review of Related Literature}

\subsection{Related Literature}

\subsubsection{Knowledge Management Concept}

Fundamentally, knowledge management is about applying the collective knowledge of the entire workforce to achieve specific organizational goals. The aim of knowledge management is not necessarily to manage all knowledge, but rather just the knowledge that is most important to the organization. It is about ensuring that people have the knowledge they need, where they need it, when they need it - the right knowledge, in the right place, at the right time (De Brun, 2005). Thus, knowledge becomes an essential organizational driver and a key factor in value creation. Increased focus must be placed on expanding the organizational knowledge base, either by learning from others (e.g. colleagues, partners, third party content, etc.) or by creating new knowledge through innovation. Both processes help secure a sustainable competitive advantage (Bornemann et al., 2003). Knowledge management is not so much a new practice as it is an integrating practice. It offers a framework for balancing the myriad of technologies and approaches that provide value, tying them together into a seamless whole. It helps analysts and designers better address the interests of stakeholders across interrelated knowledge flows and, by doing so, better enables individuals, systems and organizations to exhibit truly intelligent behavior in multiple contexts (Wiig, 1995).

\subsubsection{Benefits of Knowledge Management Application}

Many researchers tried to identify the benefits of knowledge management application (Wiig, 1994; Al-Refaee \& Yaseen, 2004). The results of such studies found that the benefits of knowledge management application were the following: (Abu-Khdair, 2009)

a. Improvement of the decision making process, which led to decisions being made by lower administrative levels using minimum human resources.

b. Better implementation of these decisions, because of the shorter communication links.

c. Using the increased knowledge; employees become more capable of doing their duties, and other duties related to their jobs.

d. Employees became more aware of the work flow in the organization, which helped in the improvement of the overall organizational effectiveness.

e. Increased capability of the organization to satisfy customers, through improved products, services and efficient responses.

f. Improvement of internal processes, which lead to decreased costs at the organization.

\subsubsection{Knowledge Management Processes}

From an administrative perspective, organizational knowledge management is the practice of seeking to acquire, develop and distribute knowledge between the members of the organization to achieve the most organizational efficiency. This is clear from the definitions across most of the literature review. Thus, it is defined as: the process of acquiring or depositing knowledge and using it to improve the organizational performance (Boisot, 1997). Also, it is defined as: the process of storing knowledge and using it to achieve organizational activities on the basis of originally existing knowledge, and working to develop it in the future (Mayo, 1998). 
Most concepts and administrative schools looked at knowledge management as a process. Thus, knowledge from information which comes from external and internal resources will not mean anything without those processes that help in using it for application or re-suing it. Knowledge management is related to, and every one of these processes supports each other, as follows: (Darwaza, 2008)

1. Knowledge Identification: Refers to the process of making policies and programs for other processes. Thus, the purpose of knowledge identification is to identify the type of available knowledge, and matching it against what is needed to be done.

2. Knowledge Generation: This process refers to knowledge innovation in the organization. This involves team participation in generating new knowledge capital, and their work on new cases and practices to identify problems and solve them.

3. Knowledge Distribution: If the organization didn't distribute the knowledge in an efficient way, there will be no return from the costly knowledge management process. Thus. if it is easy to distribute clear knowledge using technology, then implicit knowledge of the employees must be distributed using the same way. This process is considered as the biggest challenge in the face of knowledge management.

4. Knowledge Application: The purpose and objective of knowledge management is applying the available knowledge in the organization, so it is considered as the most important process in knowledge management. This include: (use, reuse and utilization) of knowledge.

\subsection{Previous Studies}

Al-Faris (2010) conducted a study aimed at identifying the role of knowledge management in improving the level of performance of internal processes. It was conducted on ten newly established companies in accordance with the Investment Promotion Law (1991). Data was collected primarily through a questionnaire prepared for this purpose, along with a limited number of interviews. The study was conducted over a period of five years (2003-2007).

The study results showed the existence of a strong correlation between knowledge management and performance; allowing the researcher to conclude that the findings were applicable and usable.

Also, Mohammed (2010) conducted a study investigating the impact of prevalent knowledge management in achieving a competitive advantage. The sample consisted of (84) Singles of the governing body at Jordan Telecom Group, and was tested using simple regression analysis, and an analysis of variance.

Results of the study showed the presence of a high correlation between the independent variable (knowledge management processes), and between the dependent variable (competitive advantage). Also, the results indicated that there were significant differences in the impact of knowledge management processes in achieving a competitive advantage due to experience, while there were no significant differences attributable to the job description.

A study conducted by Al-Amoush (2009) was aimed at identifying the level of implementation of knowledge management in the Capital Security Force Leadership. The aspects covered were; areas of leadership, information technology, formulation of the vision and plan, generation of knowledge, transfer and dissemination of ID, investment and employment of knowledge, mechanisms of integration of knowledge, and the necessary environment for the prosperity of knowledge. The study population consisted of all individuals working in the Capital Region, which included (4) directorates of police, (24) security stations, other departments of the central leadership of the region, and (3934) recruits, male and female. The sample consisted of (276) recruits, male and female, working in the Capital Security Force Leadership, representing a rate $(7.01 \%)$ of the study, and were selected at random.

The study found that the level of implementation of knowledge management in the Capital Security Force Leadership, as seen by the researched sample was high, with an arithmetic average of (3.89). Their highest estimations on the level of implementation of knowledge management was: the generation of knowledge, the formulation of the vision and plan, the transfer and dissemination of knowledge, information technology, investment and employment of knowledge, leadership, and knowledge integration mechanisms, and the necessary environment for the flourishing of knowledge respectively.

Also, Darwaza (2008) conducted a study aimed at revealing the relationship between the requirements of knowledge management as contained in the King Abdullah the Second Award for Excellence in Corporate Performance and Transparency (knowledge requirements, knowledge awareness and commitment, internal and external communications), and the processes of knowledge management (diagnosis, generation, storage, distribution, and application). The study also looked at the impact of this relationship on the organizational performance in the Ministry of Higher Education of Jordan, from a theoretical and practical perspective. To 
achieve the objective of the study, a questionnaire was designed to gather preliminary information from members of the study.

Results of the study showed a statistically significant relationship between the requirements of knowledge management and all of; diagnostic knowledge, knowledge generation, storage of knowledge, distribution of knowledge, and application of knowledge.

McCall et al. (2008) conducted a study aimed at investigating whether the knowledge management systems embodied within public knowledge stimuli, affect performance decisions within decision-making circles, and whether knowledge is acquired in a form different from conventional methods and references (articles and books) during research and problem-solving. An empirical approach was used to study performance levels and public knowledge acquisition through a sample containing (188) volunteers, divided into two groups using knowledge management systems in one group, and conventional methods in the other.

The study found that the users of knowledge management systems outperformed the users of conventional references. There were also improvements in analysing and solving problems, the break-down of rules and definitions, and recognizing data. The difference in the performance of knowledge acquisition was statistically significant between the two groups.

Misar et al., (2001) conducted a study aimed at providing a general framework for structuring knowledge management in governmental organizations, and its most important aspects which included; human resources, technology, operations, and management. The study provided an example of the structure of knowledge management in the Indian government and the extent of success achieved from the adoption of this methodology in the Indian government.

A study conducted by Al-Mshari et al., (2002) focused on the impact of knowledge management on organizational performance based on surveys applied to institutions in Kuwait. The study sample consisted of (40) governmental institutions and (37) private foundation. Questionnaires were used to gather information from members of the study.

The study found that there was an impact of knowledge management on the performance of institutions in both its public and private sectors.

\section{Study Hypotheses}

The current study aims at testing the following hypothesis:

There is no statistically significant effect for the application of knowledge management on the effectiveness of internal processes at the Arab Banking Corporation (ABC/Jordan).

From this main hypothesis, the following sub-hypotheses were derived:

1. There is no statistically significant effect for knowledge identification on the effectiveness of internal processes at the Arab Banking Corporation (ABC/Jordan).

2. There is no statistically significant effect for knowledge generation on the effectiveness of internal processes at the Arab Banking Corporation (ABC/Jordan).

3. There is no statistically significant effect for knowledge distribution on the effectiveness of internal processes at the Arab Banking Corporation (ABC/Jordan).

4. There is no statistically significant effect for knowledge application on the effectiveness of internal processes at the Arab Banking Corporation (ABC/Jordan).

\section{Research Methodology and Techniques}

\subsection{Research Methodology}

This study utilized an analytical-descriptive methodology. Thus, a questionnaire was developed using literature review, to collect data from the study sample to identify the application of knowledge management at the Arab Banking Corporation (ABC/Jordan), and its effect on the level of effectiveness of internal processes.

\subsection{Study Sample and Population}

The study population consisted of all (510) employees working at the Arab Banking Corporation (ABC/Jordan). Due to the large number of employees, a sample was selected randomly to cover the entire population. The sample selected was (100) employees, with a percentage of (20\%) of the study population.

\subsection{Study Tool}

A questionnaire was designed depending on literature review and previous studies. The questionnaire consisted of 
two main parts, the first part: the fields of knowledge management application (knowledge identification, knowledge generation, knowledge distribution and knowledge application), and the second part: a measure of the level of effectiveness of internal processes at the Arab Banking Corporation (ABC/Jordan).

\subsection{Study Tool Validity and Reliability}

The validity of the study sample, language of the paragraphs, and suitability for their applicable domain was ensured through a number of academic specialists in the field. Also the reliability of the study instrument was confirmed by a retesting method, were a number of questionnaires were distributed on a sample reconnaissance, and then re-distributed two weeks later to the same individuals. Then, the (Chronbach alpha) factors were extracted and found to be between (0.82-.094), which is acceptable for the purposes of this study being higher than the minimum of the stability of (0.60), thus ensuring the reliability of the study tool.

\section{Study Results}

A Likert-Scale was used in developing the study questionnaire, and to answer the questionnaire items, according to the following values: strongly agree (5), agree (4), agree to some extent (3), disagree (2), strongly disagree (1). Thus, we have the following categories:

- $1-2.33 \rightarrow$ low.

- 2.34-3.66 $\rightarrow$ moderate.

- 3.67-5 $\rightarrow$ high.

\subsection{Answering Study Questions}

\subsubsection{First Question}

What is the level of knowledge management application at the Arab Banking Corporation ( $\mathrm{ABC} / \mathrm{Jordan})$ ?

To answer this question, arithmetic means and standard deviations were calculated for the fields of knowledge management applications, as shown in table 1 below.

Table 1. Arithmetic Means and Standard Deviations for the Answers of Study Sample on Knowledge Management Items

\begin{tabular}{|c|c|c|c|c|}
\hline Number & Item & $\begin{array}{l}\text { Arithmetic } \\
\text { Mean }\end{array}$ & $\begin{array}{l}\text { Standard } \\
\text { Deviation }\end{array}$ & $\begin{array}{l}\text { Level of } \\
\text { Importance }\end{array}$ \\
\hline \multicolumn{5}{|c|}{ Knowledge Identification } \\
\hline 1 & Management depends on presentations about knowledge maps (charts and semantic). & High & 0.96 & 4.15 \\
\hline 2 & The Bank especially designed a map of knowledge and experience of the Interior. & High & 0.94 & 3.96 \\
\hline 3 & The bank uses benchmarks internally and externally. & Moderate & 1.13 & 3.55 \\
\hline 4 & The bank depends in work style on bulletins of creativity. & High & 0.95 & 3.84 \\
\hline$\underline{5}$ & The Bank has a portfolio of knowledge about the internal external knowledge. & Moderate & 1.10 & 3.49 \\
\hline \multicolumn{5}{|c|}{ Knowledge Generation } \\
\hline 6 & Generation of knowledge is done by acquisition from external resources. & High & 0.96 & 3.74 \\
\hline 7 & $\begin{array}{l}\text { The Bank follows the method of knowledge generation in the systemic treatment of tacit } \\
\text { knowledge (development of an educated class) from the inside. }\end{array}$ & High & 0.98 & 3.79 \\
\hline 8 & Formation of teams with diverse learning cognitive internal experts and continuously. & Moderate & 0.86 & 3.60 \\
\hline 9 & The Bank follows in the generation of knowledge learning organizational workshops. & Moderate & 0.97 & 3.62 \\
\hline 10 & The Bank use future simulations method (learning scenarios) in the generation of knowledge. & High & 0.96 & 3.74 \\
\hline \multicolumn{5}{|c|}{ Knowledge Distribution } \\
\hline 11 & The Bank distributes knowledge internally through various cognitive differences. & Moderate & 1.04 & 3.60 \\
\hline 12 & $\begin{array}{l}\text { The Bank has an internal information network to gain access to databases (computers, } \\
\text { archiving system). }\end{array}$ & Moderate & 1.02 & 3.58 \\
\hline 13 & Technology of experienced people is used during the individual distribution of knowledge. & Moderate & 1.04 & 3.60 \\
\hline 14 & $\begin{array}{l}\text { The Bank follows the method of training by veterans experienced colleagues in order to } \\
\text { improve operations and reduce costs. }\end{array}$ & Moderate & 1.02 & 3.58 \\
\hline 15 & Bank supports an internal mechanism for the publication and dissemination of knowledge. & Moderate & 1.14 & 3.40 \\
\hline \multicolumn{5}{|c|}{ Knowledge Application } \\
\hline 16 & The bank has various internal experienced independent teams. & Moderate & 0.99 & 3.41 \\
\hline 17 & The Bank applies continuously initiatives and programs related to knowledge. & Moderate & 1.05 & 3.46 \\
\hline 18 & Bank relies on the opinion on the internal expert about the results of its operations and activities & Moderate & 1.05 & 3.51 \\
\hline 19 & The Bank uses several measures to control the applied knowledge. & High & 0.96 & 3.69 \\
\hline \multirow[t]{2}{*}{20} & The Bank is continuously train staff by experienced experts internally and externally. & High & 1.03 & 3.74 \\
\hline & Total Mean & Moderate & 1.00 & 3.65 \\
\hline
\end{tabular}


After calculating the total arithmetic mean for the fields of knowledge management, we notice that it reached (3.65) with a standard deviation of (1.00), and a moderate level of importance. This indicates that: "The level of application of knowledge management at the Arab Banking Corporation (ABC/Jordan) was moderate".

\subsubsection{Second Question}

What is the level of effectiveness of internal processes at the Arab Banking Corporation (ABC/Jordan)?

To answer this question, arithmetic means and standard deviations were calculated for the field of internal processes effectiveness, as shown in the following table 2 .

Table 2. Arithmetic Means and Standard Deviations for the Answers of Study Sample on internal processes effectiveness Items

\begin{tabular}{|c|c|c|c|c|}
\hline Number & Item & $\begin{array}{l}\text { Arithmetic } \\
\text { Mean }\end{array}$ & $\begin{array}{l}\text { Standard } \\
\text { Deviation }\end{array}$ & $\begin{array}{l}\text { Level of } \\
\text { Importance } \\
\end{array}$ \\
\hline 1 & Bank is keen to ensure the quality of services. & High & 0.96 & 3.74 \\
\hline 2 & Services at the bank have flexibility. & High & 0.93 & 3.76 \\
\hline 3 & Bank is keen to establish strategic partnerships to develop the services it provides. & Moderate & 0.86 & 3.60 \\
\hline 4 & Bank is keen to establish strategic partnerships to develop the services it provides. & High & 0.89 & 3.90 \\
\hline 5 & Re-design of services is based on the to customer feedback. & High & 0.96 & 3.88 \\
\hline 6 & Bank seeks to provide the service on time. & High & 0.96 & 3.77 \\
\hline 7 & Apply the Bank corporate governance procedures. & High & 0.93 & 3.79 \\
\hline 8 & The health of the staff of the priorities of the Bank's attention. & High & 0.98 & 3.79 \\
\hline 9 & Bank is keen to open up multiple channels for receiving customer complaints. & High & 0.91 & 3.81 \\
\hline \multirow[t]{2}{*}{10} & Bank is keen to introduce new technologies to improve service delivery. & Moderate & 0.97 & 3.62 \\
\hline & Total Mean & High & 0.93 & 3.76 \\
\hline
\end{tabular}

After calculating the total arithmetic mean for the fields of internal processes effectiveness, we noticed that it reached (3.67) with a standard deviation of (0.93), and a high level of importance. This indicated that: "The level of effectiveness of internal processes at the Arab Banking Corporation (ABC/Jordan) was high".

\subsection{Testing Study Hypotheses}

\subsubsection{Main Hypothesis}

There is no statistically significant effect of knowledge management application on internal processes effectiveness at the Arab Banking Corporation (ABC/Jordan).

To test this hypothesis, the multiple regression method was used. Table 3 below shows the results.

Table 3. Multiple Regressions to Test the Effect of Knowledge Management Application on Internal Processes Effectiveness at the Arab Banking Corporation (ABC/Jordan)

\begin{tabular}{llll}
\hline Sig & F & R square & R \\
\hline 0.00 & 44.45 & 0.43 & 0.66 \\
\hline
\end{tabular}

From the previous table 3, we notice that the value of the correlation coefficient $(\mathrm{R})$ between the fields of knowledge management in the Arab Banking Corporation (ABC/Jordan) reached (66\%), and the coefficient of determination (R2) reached (43\%). This means that (43\%) of the changes in the fields of application of knowledge management resulted from the combined variations in the application fields. Confirming this effect is the value of (F), which amounted to (44.45), with a level of significance less than (0.05), which indicates a significant effect of the application of the principles of knowledge management on the effectiveness of internal processes in the Arab Banking Corporation (ABC/Jordan).

To test the sub-hypotheses, beta, (T) values, and Sig. levels were calculated, as shown in the following table 4 .

Table 4. Beta, (T), sig. values for knowledge management fields

\begin{tabular}{llll}
\hline Sig. & $\mathrm{T}$ & Beta & Variables \\
\hline 0.00 & -6.50 & -0.29 & Knowledge identification \\
0.91 & -0.12 & -0.01 & Knowledge Generation \\
0.11 & -1.60 & -0.07 & Knowledge Distribution \\
0.00 & -4.63 & -0.20 & Knowledge Application \\
\hline
\end{tabular}


The following are the results of testing the sub-hypotheses:

\subsubsection{First Sub-hypothesis}

There is no statistically significant effect of knowledge identification on the effectiveness of internal processes at the Arab Banking Corporation (ABC/Jordan).

From table 4 above, we notice that the beta value reached (-0.29), and the (T) value was (-6.50) with a Sig. of $(0.00)$, which is less than the significant level of (0.05). This means that we reject the null hypothesis, and accept the alternative hypothesis, which states that: "There is a statistically significant effect of knowledge identification on the effectiveness of internal processes at the Arab Banking Corporation (ABC/Jordan)".

\subsubsection{Second Sub-hypothesis}

There is no statistically significant effect of knowledge generating on the effectiveness of internal processes at the Arab Banking Corporation (ABC/Jordan).

From table 4 above, we notice that the beta value reached $(-0.01)$, and the $(\mathrm{T})$ value was $(-0.12)$ with a Sig. of (0.91), which is more than the significant level of (0.05). This means that we reject the alternative hypothesis, and accept the null hypothesis, which states that: "There is no statistically significant effect of knowledge generation on the effectiveness of internal processes at the Arab Banking Corporation (ABC/Jordan)".

\subsubsection{Third Sub-hypothesis}

There is no statistically significant effect of knowledge distribution on the effectiveness of internal processes at the Arab Banking Corporation (ABC/Jordan).

From table 4 above, we notice that the beta value reached $(-0.07)$, and the $(T)$ value was $(-1.60)$ with a Sig. of (0.11), which is more than the significant level of (0.05). This means that we reject the alternative hypothesis, and accept the null hypothesis, which states that: "There is no statistical significant effect of knowledge distribution on the effectiveness of internal processes at the Arab Banking Corporation (ABC/Jordan)".

\subsubsection{Fourth Sub-hypothesis}

There is no statistically significant effect of knowledge application on the effectiveness of internal processes at the Arab Banking Corporation (ABC/Jordan).

From table 4 above, we notice that the beta value reached $(-0.20)$, and the $(\mathrm{T})$ value was $(-4.63)$ with a Sig. of $(0.00)$, which is less than the significant level of $(0.05)$. This means that we reject the null hypothesis, and accept the alternative hypothesis, which states that: "There is a statistically significant effect of knowledge application on the effectiveness of internal processes at the Arab Banking Corporation (ABC/Jordan)".

\section{Conclusion}

The results of this study showed that there is a moderate level of application of knowledge management fields. This result is reasonable, because this concept is relatively new in modern management and needs some time before being fully utilized in most organizations. This result is different from the results of the study conducted by Al-Amoush (2009), which showed that the level of application of knowledge management in the Capital Security Force Leadership, as seen by the researched sample was high.

Also, results showed a high level of effectiveness of internal processes at the Arab Banking Corporation (ABC/Jordan). This result can be due to the nature of work at the banking sector, which demands a very narrow margin of error, thus making the effectiveness of internal processes high.

On the other hand, statistical analysis revealed that there was a statistically significant effect due to knowledge management application on the level of internal processes effectiveness. This may be due to the high relativity of the two variables. As a result, all the fields of knowledge management (knowledge diagnosis, knowledge generation, knowledge distribution, and knowledge application) play an important role in the banking internal processes. This result is similar to the results of a study conducted by Al-Faris (2010), which showed a strong correlation between knowledge management and performance.

In light of these results, the study recommends, and stresses the importance of, a system of incentives to encourage employees to participate at the bank, include the expertise and skill set they possess, and urge them to apply and distribute their knowledge. Also, it recommends a monitoring of all the developments in the field of information technology, and the use of modern management information systems, in addition to all other applications, for the development of modern means that help store and generate investments and bring about sustainable development. Finally, the study recommends making further studies looking into the factors affecting the effectiveness of internal processes in the organization. 


\section{References}

Abu Khadir, E. S. (2009). Applications of knowledge management in institutions of higher education: ideas and practices. Research presented to the International Conference for Administrative Development: Towards an outstanding performance in the government sector. held at the Institute of Public Administration.

Al-Amoush, A. A. M. (2009). The level of knowledge management in the leadership of the security of the territory of the capital of Jordan. (Unpublished MA Thesis). University of Al al-Bayt, Karak, Jordan.

Al-Faris, S. (2010). The role of knowledge management in raising the efficiency of the performance of organizations: a field study on the manufacturing companies of Damascus. Damascus University Journal of Economics, legal, 26(2).

Al-Khalili, S. M. T. (2006). The role of knowledge management in the Ministry of Education of Jordan Aterbah: an analytical study. (Unpublished MA Thesis). Yarmouk University, Irbid, Jordan.

Al-Mashari, M., Zairi, M., \& Al-Athari, A. (2002). An Empirical Study of the impact of Knowledge Management on Organizational Performance. Journal of Computer Information Systems, Special Issue.

Boisot, M. (1997). Information and Organizations. The Managers as Anthropologist, London.

Bornemann, M., Graggober, M., Hartieb, E., Hympl, B., Koronakis, P., Primus, A., . . . Wols, K. (2003). An Illustrated Guide to Knowledge Management. Wissensmanagement Forum, Graz, Austria.

Darwaza, S. S. (2008). The relationship between the requirements of knowledge management and operations and their impact on organizational performance excellence: applied study in the Ministry of Higher Education in Jordan. (Unpublished MA Thesis). University of the Middle East for Graduate Studies, Amman, Jordan.

De Brun, C. (2005). ABC of Knowledge Management. National Library for Health: Knowledge Management Specialist Library. Available at the world wild web: http://www.library.nhs.uk/knowledgemanagement.

Kasasbeh, S. M. A. (2011). The impact of intellectual capital on the effectiveness of internal processes in telecommunications companies in Jordan. (unpublished PhD thesis). Amman Arab University for Graduate Studies, Amman, Jordan.

Mayo, A. (1998). Memory Bankers. People Management, 4(2).

McCall, H., Arnold, V., \& Sutton, S. (2008). Use if Knowledge Management systsems and the Impact of the Acqusition of Explicit Knowledge. Journal of Information Systems, 22(2), 77-101. http://dx.doi.org/10.2308/jis.2008.22.2.77

Misra, D. C., Rama, H., \& Manie, K. (1990). E-Knowledge Management Framework for Government Organizations. Information Systems Management, spring, 2003, Yarmouk University. Database.

Mohammed, F. (2010). Knowledge management processes and their impact in achieving competitive advantage: a case study of Jordan Telecom Group. International Forum on the fourth: competition and competitive strategies of the industrial enterprises outside the hydrocarbon sector in Arab countries.

Wiig, K. M. (1995). Knowledge Management Methods: Practical Approaches to Managing Knowledge. Arlington, Texas, Schema Press. 